\title{
Enraizamento de estacas semilenhosas de maracujazeiro amarelo (Passiflora actinia Hook)
}

\section{Rooting of yellow native Passionfruit by semi-hardwood cuttings}

\author{
Celso Lopes de Albuquerque Junior ${ }^{*}$; Moeses Andrigo Danner²; Luiz Alberto \\ Kanis $^{3}$; Cícero Deschamps ${ }^{4}$; Flavio Zanette ${ }^{4}$; Patrícia Menegaz de Farias ${ }^{5}$
}

\begin{abstract}
Resumo
O maracujazeiro amarelo (Passiflora actínia) é uma espécie heliófita, nativa do Brasil, resistente a baixas temperaturas e com grande potencial para ser utilizada como porta-enxerto para $P$. alata e $P$. quadrangularis. $\mathrm{O}$ objetivo deste trabalho foi avaliar a influência do tipo de estaca, quanto à sua posição no ramo (basal, mediana e apical) e à presença de folhas, no enraizamento de estacas semilenhosas de Passiflora actinia. Foram utilizadas estacas com dois nós $(8$ a $10 \mathrm{~cm})$ e tubetes contendo vermiculita, mantidos em casa-de-vegetação sob nebulização intermitente, durante 90 dias. O delineamento experimental foi em blocos ao acaso, com quatro repetições, em esquema bifatorial (posição da estaca no ramo x presença ou ausência de folhas), sendo cada parcela composta por 12 estacas. Após os 90 dias, foram avaliados a porcentagem de estacas enraizadas, o número de raízes formadas, a massa de matéria seca $(\mathrm{g})$ e o comprimento médio das três maiores raízes $(\mathrm{cm})$. Verificou-se que houve interação significativa entre os fatores posição do ramo e presença ou ausência de folhas nas estacas para todas as variáveis estudadas. Concluiu-se que as estacas basais com a presença de folhas proporcionaram o maior percentual de enraizamento, além de maior número de raízes, maior massa de matéria seca e maior comprimento das raízes.
\end{abstract}

Palavras-chave: Passifloraceae, estaquia, propagação vegetativa

\begin{abstract}
Native yellow passionfruit (Passiflora actinia) is a heliophytic species, native to Brazil, resistant to low temperatures and with great potential to be used as rootstock for P. alata and P. quadrangularis. The objective of this study was to evaluate the influence of type of cuttings related to their position in the branch (basal, middle and apical) and the presence of leaves on rooting of cuttings of Passiflora actinia. Cuttings with two nodes were prepared $8-10 \mathrm{~cm}$ long, and then planted in plastic pots containing vermiculite and maintained in a greenhouse under intermittent mist for 90 days. We evaluated the percentage of rooted cuttings, number of roots, dry weight and length of roots. The statistical design was randomized blocks with 6 treatments, each treatment consisted of four replications with 12 cuttings each. We performed analysis of variance and Tukey's test to the data interpretation. It was concluded that the presence of leaves on the basal cuttings showed the highest rooting percentage, the greatest number of roots, highest dry weight and greatest length of roots.
\end{abstract}

Key words: Passifloracea, cuttings, vegetative propagation

\footnotetext{
${ }^{1}$ Eng $^{\circ}$ Agro , Prof. Dr. do curso de agronomia, UNISUL, Universidade do Sul de Santa Catarina, Tubarão, SC. E-mail: celso. albuquerque@unisul.br

${ }^{2}$ Eng $^{\circ}$ Agr $^{\circ}$, Dr. Extensionista, EPAGRI, Empresa de Pesquisa e Extensão Rural de Santa Catarina, São Lourenço do Oeste, SC. E-mail: moesesandrigo@yahoo.com.br

${ }^{3}$ Farmacêutico, Prof. Dr. do Programa de Pós-graduação em Ciências da Saúde, UNISUL, Tubarão, SC. E-mail: luiz.kanis@ unisul.br

${ }^{4}$ Eng $^{\circ}{ }^{\text {Agr }}{ }^{{ }^{s}}$, Profs. Drs. do Programa de Pós-graduação em Produção Vegetal, Universidade Federal do Paraná, UFPR, Curitiba, PR.E-mail: cicero@ufpr.br; flazan@ufpr.br

${ }^{5}$ Eng ${ }^{\circ}$ Agra, Profa. M.e do curso de agronomia, UNISUL, Universidade do Sul de Santa Catarina, Tubarão, SC. E-mail: patricia. farias@unisul.br

* Autor para correspondência
} 
O Brasil vem se destacando como um dos principais produtores mundiais de frutas. Dentre as frutas produzidas, o maracujazeiro tem apresentado crescimento expressivo no país. Os estados da Bahia, Espírito Santo, São Paulo, Sergipe, Pará, Minas Gerais, Ceará, Rio de Janeiro e Alagoas perfazem, aproximadamente, 94\% da produção total (MELETTI, 2011).

O cultivo comercial de maracujá é, na sua quase totalidade, de Passiflora edulis Sims f. flavicarpa Deg. (maracujá-amarelo) e P. edulis Sims (maracujároxo). Embora nem todos os países cultivem a mesma espécie, Brasil, Peru, Venezuela, África do Sul, Sri Lanka, Austrália, Nova Guiné, Ilhas Fiji, Havaí, Formosa e Quênia respondem por 80 a $90 \%$ da produção mundial de maracujá (PERUCH et al, 2009).

A espécie Passiflora actinia é uma espécie heliófita, nativa do Brasil, ocorrendo principalmente no interior de florestas, estendendo seus ramos por sobre as árvores e florescendo em plena luz, sendo encontrada nos estados do Rio de Janeiro, São Paulo, Paraná, Santa Catarina e Rio Grande do Sul (LIMA; CUNHA, 2004). Essa espécie pode ser usada como porta-enxerto para $P$. alata e $P$. quadrangularis, pois tolera baixas temperaturas (PIRES et al., 2009). Devido às condições climáticas do Sul do Brasil, onde normalmente ocorrem geadas, é de grande importância preservar e domesticar essa espécie, muito apreciada por animais e explorada para alimentação humana (VANDERPLANK, 1996; LIMA et al., 2007).

A propagação do maracujazeiro pode ser realizada via semente ou pelos processos de estaquia e enxertia. Nos cultivos comerciais de maracujazeiro formados por mudas obtidas por via sexuada ocorrem variações quanto à produtividade, à forma, ao tamanho e à coloração do fruto (FONSECA, 2002). A propagação de maracujazeiro por meio da estaquia tem propiciado a obtenção e a multiplicação de plantas produtivas, tolerantes a pragas e doenças e homogêneas, características de grande interesse para a produção de porta-enxertos (LIMA; CUNHA, 2004).

Estacas utilizadas para o enraizamento do maracujazeiro devem ser obtidas de regiões da planta, apresentando dois ou três entrenós (CHAPMAN, 1963; FOUQUÉ, 1972). Além disso, a presença e o número de folhas nas estacas são fatores que podem influenciar seu enraizamento. Biasi, Pommer e Pino (1997) avaliaram o enraizamento de estacas semilenhosas de portaenxertos de videira (IAC 572 Jales e IAC 766 - Campinas) com diferentes áreas foliares $(0,25$, 50,75 e $100 \mathrm{~cm}^{2}$ ). Os autores verificaram que as folhas são indispensáveis à formação de raízes, pois a ausência destas promoveu $50 \%$ de mortalidade das estacas. Segundo Hartmann et al. (2002), as folhas influenciam positivamente no enraizamento de estacas, uma vez que fornecem uma grande quantidade de auxinas que são translocadas para a base das estacas, favorecendo o enraizamento.

O objetivo deste trabalho foi avaliar a influência do tipo de estaca relacionada à sua posição no ramo (basal, mediana e apical) e à presença ou ausência de folhas no enraizamento de estacas de maracujazeiro amarelo nativo (Passiflora actinia).

O experimento foi conduzido em casa de vegetação do Setor de Ciências Agrárias - UFPR, Curitiba, Estado do Paraná, entre os meses de agosto e novembro de 2011.

As estacas foram obtidas a partir de ramos semilenhosos do último ciclo de crescimento, com aproximadamente $30 \mathrm{~cm}$ de comprimento, de plantas matrizes com 10 anos, de maracujazeiro (Passiflora actinia), oriundas de plantio efetuado na área do Departamento de Fitotecnia e Fitossanitarismo do mesmo setor. A coleta foi realizada no período da manhã, no mesmo dia de confecção das estacas, e os ramos foram acondicionados em caixas plásticas contendo água. Após a coleta, as estacas foram submetidas a tratamento fitossanitário com hipoclorito de sódio a $0,5 \%$ por 10 minutos, e enxaguadas em água corrente durante 5 minutos. 
Em seguida, as estacas foram divididas de acordo com a posição do ramo em apicais, medianas e basais, e confeccionadas com comprimento de 8 a $10 \mathrm{~cm}$ (contendo dois nós), com corte em bisel na base e corte reto acima da última gema axilar. As estacas foram deixadas sem folhas ou com duas folhas inteiras, sendo que em ambos os tratamentos as estacas estavam sem estípulas foliáceas. Após a confecção, as estacas foram submetidas a tratamento fitossanitário com hipoclorito de sódio a $0,5 \%$, por 10 minutos, e enxaguadas em água corrente durante 10 minutos. Posteriormente, foram transferidas para tubetes de polipropileno com capacidade de $53 \mathrm{~cm}^{3}$, contendo vermiculita de granulometria fina como substrato (LIMA et al., 2007; MARTINS et al., 2012).

As estacas foram mantidas em casa-de-vegetação com umidade relativa de aproximadamente 90\% e temperatura média de $25{ }^{\circ} \mathrm{C}$. Para manter essas condições, foi utilizado um sistema de nebulização intermitente (15 segundos de irrigação a cada 15 minutos) composto por microaspersores tipo "bailarina" com vazão de 70 1/hora. Após 90 dias do plantio, foram avaliados a porcentagem de estacas enraizadas, o número de raízes formadas, a massa de matéria seca (g) que foi obtida pela secagem das raízes a $65^{\circ} \mathrm{C}$ em estufa com ventilação forçada até a obtenção da massa constante, e o comprimento médio das três maiores raízes $(\mathrm{cm})$, obtido com o auxílio de uma régua .

$\mathrm{O}$ delineamento experimental utilizado foi em blocos ao acaso, com quatro repetições, no esquema fatorial $3 \times 2$ (posições do ramo x presença ou ausência de folhas). Cada unidade experimental continha 12 estacas. Os dados de percentual de enraizamento e massa seca de raízes formadas foram transformados por $\operatorname{arcsen} \sqrt{ }(x+1) / 100$; e os dados de número e comprimento de raízes formadas foram transformados por $\operatorname{arcsen} \sqrt{ }(x+10) / 100$. Os dados foram submetidos à análise de variância; e as médias, comparadas pelo teste de Tukey $(P \leq 0,05)$.

Verificou-se que houve interação significativa entre os fatores posição do ramo e presença ou ausência de folhas nas estacas para todas as variáveis estudadas (porcentagens de estacas enraizadas, número de raízes formadas, massa de matéria seca e comprimento das raízes) (Tabela 1).

Tabela 1. Análise de variância para porcentagem de estacas de Passiflora actinia enraizadas, massa seca de raízes, número médio de raízes formadas por estaca e comprimento médio de raízes. UFPR, Curitiba, PR, 2011.

\begin{tabular}{|c|c|c|c|c|c|}
\hline \multirow[b]{2}{*}{ Fator de Variação } & \multicolumn{5}{|c|}{ Quadrado Médio } \\
\hline & $\begin{array}{l}\text { Graus de } \\
\text { liberdade }\end{array}$ & $\begin{array}{c}\text { Enraizamento } \\
(\%)^{1} \\
\end{array}$ & $\begin{array}{c}\text { Massa } \\
\text { Seca }(g)^{1} \\
\end{array}$ & $\begin{array}{l}\text { Número de } \\
\text { raízes }^{2}\end{array}$ & $\begin{array}{l}\text { Comprimento de } \\
\text { raízes }(\mathrm{cm})^{2}\end{array}$ \\
\hline Local ou Bloco & 3 & $0,020 * *$ & $0,016^{*}$ & $0,009^{* *}$ & $0,141^{*}$ \\
\hline Posição das Estacas (F1) & 2 & $40,433 * *$ & $17,050 * *$ & $111,710 * *$ & $186,247 * *$ \\
\hline Estacas com e sem folhas (F2) & 1 & $19,075^{* *}$ & $17,144 * *$ & $106,510 * *$ & $122,060 * *$ \\
\hline $\mathrm{F} 1 \mathrm{xF} 2$ & 2 & $5,975 * *$ & $6,628 * *$ & $56,650 * *$ & $51,713 * *$ \\
\hline Resíduo & 15 & 220,563 & 0,391 & 1,777 & 2,737 \\
\hline Total & 23 & & & & \\
\hline $\mathrm{CV} \%$ & & 14,260 & 10,090 & 6,840 & 8,38 \\
\hline
\end{tabular}

** significativo ao nível de $1 \%$ de probabilidade $(\mathrm{p} \leq 0.01) ;{ }^{*}$ significativo ao nível de $5 \%$ de probabilidade $(0,01<P \leq 0,05)$; ${ }^{\text {ns }}$ não significativo $(P>0,05) ;{ }^{1}$ Dados transformados por $\operatorname{arcsen} \sqrt{ }(\mathrm{x}+1) / 100 ;{ }^{2}$ Dados transformados por $\mathrm{x}=\operatorname{arcsen} \sqrt{ }(\mathrm{x}+10) / 100$.

Fonte: Elaboração dos autores. 
Houve enraizamento apenas nas estacas das posições basal e mediana do ramo. Os maiores índices de enraizamento foram obtidos nos tratamentos com estacas basais com folhas e estacas medianas com folhas, sendo superiores aos tratamentos de estacas sem folhas, em ambas as posições do ramo (Tabela 2). Esse mesmo padrão de resultados se repetiu para as demais variáveis do enraizamento, sendo que o número médio de raízes formadas, a massa de matéria seca e o comprimento das raízes foram maiores em estacas da posição basal em relação à posição mediana do ramo e em estacas com folhas em comparação às sem folhas. As estacas oriundas da posição apical do ramo morreram e consequentemente não enraizaram, independente de conter ou não folhas.

Tabela 2. Efeito do tipo de estaca relacionada à sua posição no ramo e da presença ou ausência de folhas nas estacas, na porcentagem de enraizamento, no número médio, comprimento e massa seca de raízes formadas em estacas semilenhosas de Passiflora actinia. UFPR, Curitiba, PR, 2011.

\begin{tabular}{cccccccccccccccccccc}
\hline & \multicolumn{3}{c}{$\begin{array}{c}\text { Estacas enraizadas } \\
(\%)\end{array}$} & \multicolumn{4}{c}{ Número de raízes } & \multicolumn{4}{c}{$\begin{array}{c}\text { Comprimento de raízes } \\
(\mathrm{cm})\end{array}$} & \multicolumn{3}{c}{$\begin{array}{c}\text { Massa seca de raízes } \\
(\mathrm{g})\end{array}$} \\
\hline $\begin{array}{c}\text { Tipo de } \\
\text { estaca }\end{array}$ & \multicolumn{3}{c}{ Com folha } & Sem folha & Com folha & Sem folha & Com folha & Sem folha & Com folha & Sem folha \\
\hline Basal & 75,0 & $\mathrm{Aa}$ & 33,3 & $\mathrm{Ab}$ & 4,21 & $\mathrm{Aa}$ & 0,75 & $\mathrm{Ab}$ & 5,02 & $\mathrm{Aa}$ & 1,81 & $\mathrm{Ab}$ & 0,54 & $\mathrm{Aa}$ & 0,11 & $\mathrm{Ab}$ \\
Mediana & 41,75 & $\mathrm{Ba}$ & 18,75 & $\mathrm{Bb}$ & 1,50 & $\mathrm{Ba}$ & 0,70 & $\mathrm{Ab}$ & 1,45 & $\mathrm{Ba}$ & 0,75 & $\mathrm{Bb}$ & 0,30 & $\mathrm{Ba}$ & 0,13 & $\mathrm{Ab}$ \\
Apical & 0,0 & $\mathrm{Ca}$ & 0,0 & $\mathrm{Ca}$ & 0,0 & $\mathrm{Ca}$ & 0,0 & $\mathrm{Ba}$ & 0,0 & $\mathrm{Ca}$ & 0,0 & $\mathrm{Ca}$ & 0,0 & $\mathrm{Ca}$ & 0,0 & $\mathrm{Ba}$ \\
\hline
\end{tabular}

Médias seguidas da mesma letra maiúscula na vertical, para tipo de estaca, e médias seguidas da mesma letra minúscula na horizontal, para presença ou ausência de folhas, não diferem significativamente pelo teste Tukey $(P \leq 0,05)$.

Fonte: Elaboração dos autores.

Segundo Hartmann et al. (2002), dependendo da posição no ramo em que são retiradas, as estacas possuem condições fisiológicas diferenciadas, podendo apresentar maior conteúdo de carboidratos, substâncias nitrogenadas, aminoácidos, auxinas e compostos fenólicos. Tais compostos, quando em proporções e concentrações adequadas, acumulamse na zona de regeneração de raízes, contribuindo para a emissão de raízes adventícias. Quanto mais próximo da base do ramo em que as estacas são formadas, maiores são as condições que elas possuem para a formação da muda.

A presença de folhas nas estacas foi essencial para proporcionar maior enraizamento. De acordo com Hartmann et al. (2002), o efeito benéfico da presença das folhas em estacas semilenhosas para o enraizamento é atribuído à produção de auxinas e cofatores, que são transportados para a base das estacas e pela continuação do processo da fotossíntese, responsável pela síntese de carboidratos necessários como fonte de energia para formação e crescimento das raízes.

No presente trabalho, observou-se que existe uma compensação benéfica na capacidade de enraizamento das estacas quando elas possuem folhas. Segundo Lima et al. (2007), a presença das folhas é indispensável à formação de novas raízes, possivelmente por aumentar a quantidade de fotoassimilados translocados para a base da estaca. Esse efeito pode ser bem observado quando comparamos os dados de percentagem de estacas enraizadas em relação a sua posição no ramo. Nas estacas basais sem folhas o enraizamento foi de $33,33 \%$ e nas estacas medianas com folhas o enraizamento foi de $41,66 \%$. Esses dados mostraram que embora as estacas basais sejam mais propícias ao enraizamento, a utilização de estacas medianas com folhas atenua esse efeito da origem da estaca de acordo com a sua posição no ramo, contribuindo assim para o enraizamento. 
Segundo Lima et al. (2007), a presença de uma maior área foliar na ausência das estípulas favorece a porcentagem de enraizamento e a qualidade da raiz formada em Passiflora actinia. Esses autores obtiveram $68 \%$ de enraizamento nas estacas com uma folha. No presente experimento, o enraizamento foi ainda maior $(75,0 \%)$, provavelmente por terem sido mantidas duas folhas, o que reforça o efeito benéfico da presença das folhas. Ambos os resultados estão de acordo com os obtidos por Almeida, Boaretto e Santana (1991), Meletti e Nagai (1992), que verificaram que a presença de folhas propiciou o aumento do enraizamento de espécies comerciais de maracujazeiro (P. edulis f. flavicarpa e P. alata).

Em trabalhos conduzidos por Ruggiero e Martins (1987) com a espécie Passiflora giberti, os autores registraram $75,5 \%$ de enraizamento utilizando estacas com dois nós e duas meias folhas, e para Passiflora alata 90,5\% em estacas com um nó e meia folha, colocadas em vermiculita, sob nebulização em ripado com 50\% de luminosidade. Bordin et al. (2005) avaliando o efeito da presença de folhas no enraizamento de estacas de porta-enxertos de videira (IAC 766 e IAC 572), observaram que as estacas com folha inteira e com meia folha, foram superiores às estacas sem folha quanto à porcentagem de estacas enraizadas, ao número de raízes por estaca, à matéria fresca de raízes por estaca e ao comprimento de raízes por estaca.. Além disso, Corrêa e Biasi (2003) observaram que o aumento da massa seca das raízes formadas por estaca é diretamente proporcional à área foliar da mesma, ou seja, à sua área fotossintética. Esses resultados indicam que o acúmulo de massa seca nas raízes também aumenta devido à quantidade de folhas deixada nas estacas.

De acordo com os resultados obtidos, concluise que estacas semilenhosas retiradas da posição basal do ramo, com duas folhas inteiras, são as mais indicadas para a propagação de Passiflora actinia por estaquia.

\section{Referências}

ALMEIDA, L. P.; BOARETTO, M. A. C.; de SANTANA, R. G. Estaquia e comportamento de maracujazeiros (Passiflora edulis Sims f. flavicarpa Deg.) propagados por via sexual e vegetativa. Revista Brasileira de Fruticultura, Cruz das Almas, v. 13, n. 1, p. 157-159, 1991.

BIASI, L. A.; POMMER, C. V.; PINO, P. A. G. S. Propagação de porta-enxertos de videira mediante estaquia semilenhosa. Bragantia, Campinas, v. 56, n. 2, p. 367-376, 1997.

BORDIN, I.; HIDALGO, P. C.; BÜRKLE, R.; ROBERTO, S. R. Efeito da presença da folha no enraizamento de estacas semilenhosas de porta-enxertos de videira. Ciência Rural, Santa Maria, v. 35, n. 1, p. 215-218, 2005.

CHAPMAN, T. Passion fruit growing in Kenia. Economic Botany, Baltimore, v. 17, n. 3, p. 165-168, 1963.

CORRÊA, C.; BIASI, L. A. Área foliar e tipo de substrato na propagação por estaquia de cipó-milhomens (Aristolochia triangularis Cham. et Schl.). Revista Brasileira de Agrociências, Pelotas, v. 9, n. 3, p. 233-235, 2003

FONSECA, E. B. A. Crescimento do maracujazeirodoce (Passiflora alata Dryand) em função da calagem, clases do solo e tipos de muda. 2002. Tese (Doutorado em Fitotecnia) - Universidade Federal de Lavras, Lavras.

FOUQUÉ, A. Espècies frutières d'Amerique tropicale. Fruits, Paris, v. 27, n. 5, p. 369-382, 1972.

HARTMANN, H. T.; KESTER, D. E.; DAVIES JUNIOR, F. T.; GENEVE, R. L. Plant propagation: principles and pratices. 7. ed. New Jersey: Prentice-Hall, 2002. 880 p.

LIMA, A. A.; CUNHA, M. A. P. da. Maracujá: produção e qualidade na passicultura. Cruz das Almas: Embrapa, 2004.

LIMA, D. M.; ALCANTARA, G. B.; FOGAÇA, L. A.; QUOIRIN, M.; CUQUEL, F. L.; BIASI, L. A. Influência de estípulas foliáceas e do número de folhas no enraizamento de estacas semilenhosas de maracujazeiroamarelo nativo. Acta Scientiarum. Agronomy, Maringá, v. 29, p. 671-676, 2007. Suplemento.

MARTINS, C. C.; CRUZ, C. G. M.; SANTANA, D. G.; ZUCARELLI, C. Vermiculita como substrato para o teste de germinação de sementes de ipê-amarelo. Semina: Ciências Agrárias, Londrina, v. 33, n. 2, p. 533-540, 2012. 
MELETTI, L. M. M. Avanços na cultura do maracujá no Brasil. Revista Brasileira de Fruticultura, Jaboticabal, v. 33, p. 83-91, out. 2011. Número Especial.

MELETTI, L. M. M.; NAGAI, V. Enraizamento de sete espécies de maracujazeiro. Revista Brasileira de Fruticultura, Cruz das Almas, v. 14, n. 2, p. 163-168, 1992.

PERUCH, L. A. M.; SCHROEDER, A. L.; COLARICCIO, A.; GUIMARÃES, L.; CHAGAS, C. M. Doenças do maracujazeiro amarelo. Florianópolis: EPAGRI, 2009. 99 p. (Boletim técnico, 145).
PIRES, M. C.; YAMANISHI, O. K.; PEIXOTO, J. R.; JUNQUEIRA, N. T. V.; SOUSA, M. A. F. Enxertia de progênies de maracujazeiro-roxo australiano em espécies nativas. Revista Brasileira de Fruticultura, Jaboticabal, v. 31, n. 3, p. 823-830, 2009.

RUGGIERO, C.; MARTINS, A. B. G. Implantação da cultura e propagação. In: RUGGIERO, C. (Ed.). Maracujá. Jaboticabal: Legis Summa, 1987. p. 40-57.

VANDERPLANK, J. Passion flowers and passion fruit. 2. ed. Cambridge: The MIT Press, 1996. 